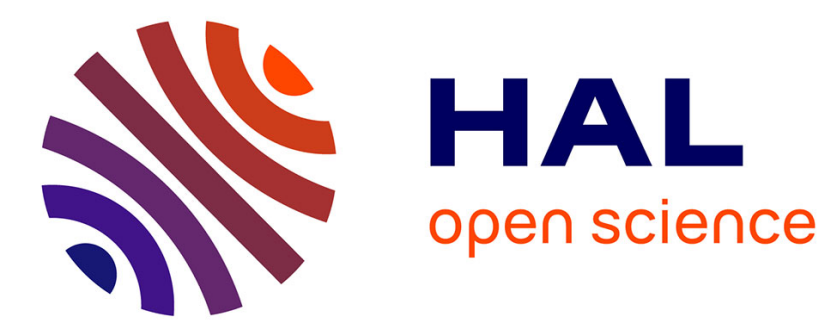

\title{
Can active labor market policy be counter-productive? Gilles Saint-Paul
}

\section{To cite this version:}

Gilles Saint-Paul. Can active labor market policy be counter-productive?. 2014. hal-01084570

\author{
HAL Id: hal-01084570 \\ https://hal-pjse.archives-ouvertes.fr/hal-01084570 \\ Preprint submitted on 19 Nov 2014
}

HAL is a multi-disciplinary open access archive for the deposit and dissemination of scientific research documents, whether they are published or not. The documents may come from teaching and research institutions in France or abroad, or from public or private research centers.
L'archive ouverte pluridisciplinaire HAL, est destinée au dépôt et à la diffusion de documents scientifiques de niveau recherche, publiés ou non, émanant des établissements d'enseignement et de recherche français ou étrangers, des laboratoires publics ou privés. 


\section{PARISSCHOQL OFECQNOMICS}

WORKING PAPER Nº $2014-38$

Can active labor market policy be counter-productive?

Gilles Saint Paul

JEL Codes: E24, J6

Keywords: Active labor market policy, Matching models

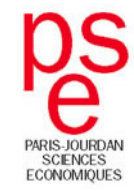




\begin{abstract}
We study active labor market policies (ALMP) in a matching model. ALMPs are modelled as a subsidy to job search. Workers differ in their productivity, and search takes place along an extensive margin. An additional job seeker affects the quality of unemployed workers. As a result, the Hosios conditions are no longer valid. To replicate the optimum the worker share in bargaining must exceed the Hosios level, and one must impose a tax on job search activity. The coalition in favor of ALMP is also studied.
\end{abstract}




\title{
Can active labor market policy be counter-productive?
}

\author{
Gilles Saint-Paul \\ Paris School of Economics \\ New York University Abu Dhabi
}

October 20, 2014 


\section{Introduction}

This paper studies the effect of active labor market policies (ALMP) in a Mortensen-Pissarides style matching model. ALMPs are modelled as a subsidy to job search, and it is assumed that search activity is observed. A key feature of the model is that workers differ in their productivity, and that search takes place along an extensive margin. The model is used to study the effect of ALMP on the equilibrium, on aggregate welfare, and, equally importantly, on the distribution of welfare across worker types (productivity levels) and current labor market status (employed vs. unemployed).

It is shown that in addition to the usual job search externality, there is a "quality" externality. As search is not directed, an additional job seeker affects the average quality of the pool of unemployed, in addition to the job finding rate. As a result, the usual "Hosios" conditions for an efficient outcome - that the bargaining share of workers match their elasticity in the matching function - are no longer valid ${ }^{1}$. For an efficient outcome, the decentralized equilbrium conditions must match the optimal ones for both the job creation margin of firms and the job search decision of workers, and these two conditions cannot be matched with a single instrument. It is shown, paradoxically, that to replicate the optimum one must select a worker share in bargaining which is larger than their elasticity in the matching function, and at the same time one must impose a tax on job search activity.

Clearly, this prediction does not validate the view that ALMPs are a desirable policy tool. The reason is that they raise workers' outside option in bargaining, thus contributing to wage pressure, while at the same time reducing the average quality of job seekers. The optimal policy outlined above delivers an improved quality of job seeker, due to the search tax, while the bargaining share in excess of the Hosios level compensates for the implied reduction in the workers' outside option.

Despite their negative effects on aggregate welfare, we can characterize

\footnotetext{
${ }^{1}$ See Hosios (1990).
} 
a coalition in favor of $\mathrm{ALMPs}^{2}$. These are favored by the least productive job seekers (or "short-term" unemployed") and the least productive workers. The former gain directly from the subsidy, and the latter gain from an enhanced outside option in bargaining. On the other hand, more productive workers and job seekers lose from it. They are harmed due to the fall in the job finding rate, which reflects in particular the deterioration in average job seeker quality. Finally, the workers who do not search (or "long term unemployed") only benefit if they are sufficiently close to the extensive margin of searching, that is, sufficiently productive. The least productive long-term unemployed are too far from the extensive margin of job search to benefit from the policy, and suffer from the financial burden of the search subsidy. Consequently, they oppose the policy. Note however that this analysis would be changed if ALMP were explicitly targeted at the least productive unemployed workers. Here, instead, by monitoring job search irrespective of productivity, the policy is implicity targeted at those workers whose productivity level is immediately below the critical search threshold.

This paper is related to the recent literature on labor market policy analysis in the context of frictional models, following Mortensen and Pissarides (2014). This literature has analyzed to some details the effect of unemployment benefits, often in the context of calibrated numerical analysis (see for example Cahuc and Lehmann (2000), Fredriksson and Holmlund (2001), Mortensen and Pissarides (2003), Lehmann and van der Linden (2007), Krusell et al. (2010), Michau (2013)). The main novelty here is the focus on ALMP and the role played by the extensive margin of job search, which introduces a new externality (See Ortega (2000) for a related effect when search is not directed and workers are heterogeneous). Also, the design of the model allows us to provide analytical results instead of relying on numerical simulations.

\footnotetext{
${ }^{2}$ The political economy of unemployed benefits was analyzed in a pioneering paper by Wright (1986). Active labor market policy was analyzed from a political economy perspective by Saint-Paul (1998, 2000). Boeri et al. (2012) focus on the arbitrage between unemployment benefits and employment protection.
} 
The paper is organized as follows. Section 2 spells out the basic framework, which is a standard matching model with heterogeneous worker productivity and a fixed search cost. Section 3 computes the equilibrium. Section 4 compares it with the utilitarian welfare optimum, and proves the first main result of the paper, i.e. that if the Hosios condition holds, the market outcome is associated with a suboptimally low job seeker quality and too much worker search, i.e. too small labor market tighter. Section 5 studies the effect on welfare of active labor market policies and shows that the first best equilibrium can be replicated if the worker bargaining share and the search subsidy are set at their optimal levels, that are characterized by a bargaining share higher than the Hosios level and a search tax. Also, I characterize the effect of ALMP on different categories of workers. There, the key result is that there exist two threshold levels for worker productivity (denoted by $y$ ), $\tilde{y}_{e}$ and $\tilde{y}_{u}$, such that $\tilde{y}_{u}>\tilde{y}_{e}$, such that the employed (resp. the unemployed job seekers) oppose an increase in the search subsidy if and only if $y>\tilde{y}_{e}$ (resp. $\left.\tilde{y}_{u}>\tilde{y}_{e}\right)$.

\section{The basic framework}

Workers differ by their productivity $y$, and the population distribution of $y$ is given by a density $\psi(y)$ and c.d.f. $\Psi(y)$. At any point in time, unemployed workers may be searching or not searching - in the latter case their utility is equal to zero. We distinguish between $u_{t}$, the total number of unemployed workers, and $\bar{u}_{t}$, those who are actively searching. The matching rate per unit of time is $m\left(\bar{u}_{t}, v_{t}\right)$ and the labor market tightness parameter $\theta$ is defined as $\theta=v / \bar{u}$. As usual, $m()$ has constant returns to scale and the vacancy filling rate is denoted by $q(\theta)=m(1 / \theta, 1)$, while the job finding rate is $\theta q(\theta)$.

In order to be searching workers must incur a unit cost equal to $d$ per unit of time. There is a constant job loss rate equal to $s$. The wage of a worker of type $y$ is denoted by $w(y)$. The value functions for being employed $V_{e}$, unemployed $V_{u}$, and the value of a job $J$ depend on the worker's type 
and their valuation equations are, assuming steady state,

$$
\begin{aligned}
r V_{u}(y) & =-d+\theta q(\theta)\left(V_{e}(y)-V_{u}(y)\right), \\
r V_{e}(y) & =w(y)+s\left(V_{u}(y)-V_{e}(y)\right), \\
r J(y) & =y-w(y)-s J(y),
\end{aligned}
$$

while wages are set by a standard Nash bargaining process with a fraction $\varphi$ of the net surplus going to the worker. This implies the following equilibrium relationship:

$$
V_{e}(y)=V_{u}(y)+\frac{\varphi}{1-\varphi} J(y) .
$$

Eliminating $V_{e}, J$, and $w$ from these 4 equations, we can get $V_{u}(y)$ for a given $\theta$ and we get

$$
r V_{u}(y)=\frac{-d(r+s)+\varphi \theta q(\theta) y}{r+s+\varphi \theta q(\theta)}
$$

It is then easy to compute the value of being employed for a worker of type $y$ :

$$
r V_{e}(y)=\frac{-d(r(1-\varphi)+s)+\varphi(\theta q(\theta)+r) y}{r+s+\varphi \theta q(\theta)} .
$$

Finally the wage is

$$
w(y)=\frac{\varphi(r+s+\theta q(\theta)) y-(1-\varphi)(r+s) d}{r+s+\varphi \theta q(\theta)} .
$$

We note that the search cost $d$ brings wages down, by reducing the opportunity cost of work.

\section{Equilibrium}

To characterize the equilibrium, we need to derive the job creation condition. We denote by $\bar{y}$ the average productivity of job applicants. The value of a worker with productivity $y$ to the firm is

$$
J(y)=\frac{y-w(y)}{r+s}=\frac{(1-\varphi)(y+d)}{r+s+\varphi \theta q(\theta)} .
$$


Free entry of vacancies implies that $E J(y)=c / q(\theta)$, where the expectations are taken with respect to the pool of job applicants. Since $J$ is linear in $y$, this is equivalent to $J(\bar{y})=c / q(\theta)$, or equivalently

$$
\bar{y}+d=\frac{c(r+s)}{(1-\varphi) q(\theta)}+\frac{\varphi}{1-\varphi} c \theta .
$$

This job creation locus defines an increasing relationship between $\bar{y}$ and $\theta$. The tighter the labor market, the greater the firms' search costs and the greater the average productivity of applicants must be to compensate.

Next, we need to know which workers search and which workers do not search. A worker of type $y$ searches, in steady state, if and only if $V_{u}(y)>0$. Using (1), we get that this is equivalent to

$$
-d(r+s)+\varphi \theta q(\theta) y>0 .
$$

Therefore, there exists a critical productivity level $y^{*}$ above which workers search, and

$$
y^{*}=\frac{d(r+s)}{\varphi \theta q(\theta)} .
$$

In steady state, the average productivity of both job applicants and employed workers is then equal to

$$
\bar{y}=E\left(y \mid y>y^{*}\right)=\frac{\int_{y^{*}}^{+\infty} y \psi(y) d y}{1-\Psi\left(y^{*}\right)} .
$$

Clearly, $d \bar{y} / d y^{*}>0$. Therefore, (3) alternatively defines a positive relationship between $y^{*}$ and $\theta$. By contrast, (4) defines a decreasing relationship between $\theta$ and $y^{*}$. When the labor market is tighter, so is the job finding rate which induces more unemployed workers to search. Accordingly the productivity threshold falls.

Equilibrium is then determined, as on Figure 1, by the intersection between the firms' job creation condition JC, defined by (3), and the worker's search condition WS, defined by (4). This intersection defines the market outcome values of $\theta$ and $y^{*}$, denoted by $\theta_{M}$ and $y_{M}^{*}$ respectively. 
Consider, for example, an increase in the workers' bargaining power $\varphi$. It shifts both loci down (Figure 2). As a result, $\theta$ unambiguously falls but $y^{*}$ may go up or down. Firms post fewer vacancies because they appropriate a smaller fraction of the surplus of the match. Workers search more for any $\theta$ because they appropriate a greater fraction of the surplus. But as $\theta$ falls, this per se discourages worker search, so that the overall effect on $y^{*}$ is ambiguous.

We can also note that in steady state, the unemployment rate is given by

$$
\begin{aligned}
u_{\infty} & =\Psi\left(y^{*}\right)+\left(1-\Psi\left(y^{*}\right)\right) \frac{s}{s+\theta q(\theta)} \\
& =\frac{s+\Psi\left(y^{*}\right) \theta q(\theta)}{s+\theta q(\theta)} .
\end{aligned}
$$

Consequently, if the net effect of an increase in $\varphi$ on $y^{*}$ is negative, it may be that the unemployment rate is lower in the long run. Despite the fall in job finding rates, expectations of appropriating a greater fraction of the surplus brings some of the "long-term unemployed" back into job search.

\section{Social welfare}

It is interesting to compare the preceding equilibrium with the social optimum. To be able to do this we need to formulate the social planner's problem adequately. There generally is an infinite number of state variables, given by the unemployment rate of type $y$ at date $t, u(t, y)$. Total output at $t$ must then be equal to

$$
y_{t}=\int_{0}^{+\infty} y(1-u(t, y)) \psi(y) d y .
$$

At each date the social planner chooses the vacancy rate $v_{t}$, or equivalently the degree of labor market tightness $\theta_{t}$, as well as the minimum productivity level $y_{t}^{*}$ for workers to search. Therefore, the evolution equations of $u(t, y)$ are given by

$$
\begin{aligned}
& \dot{u}(t, y)=s(1-u(t, y)), y<y_{t}^{*}, \\
& \dot{u}(t, y)=s(1-u(t, y))-\theta_{t} q\left(\theta_{t}\right) u(t, y), y>y_{t}^{*} .
\end{aligned}
$$


The social planner's objective function is given by

$$
\max \int_{0}^{+\infty}\left[-\left(c \theta_{t}+d\right) \bar{u}_{t}+y_{t}\right] e^{-r t} d t
$$

where $\bar{u}_{t}$, the stock of unemployed workers actively searching, is given by

$$
\bar{u}_{t}=\int_{y^{*}}^{+\infty} u(t, y) \psi(y) d y .
$$

That is, the social planner maximizes the present discounted value of output net of firms' $(c v=c \theta \bar{u})$ and workers' $(d \bar{u})$ search costs.

The co-state variable associated with $u(t, y)$ is denoted by $\left[-\lambda(t, y) e^{-r t} \psi(y)\right]$. The quantity $\lambda(t, y)$ is interpreted as the marginal social value of an additional employed worker of type $y$. We can now write down the Hamiltonian:

$$
\begin{aligned}
\mathcal{H}= & {\left[-\left(c \theta_{t}+d\right) \bar{u}_{t}+y_{t}\right] e^{-r t} } \\
& -e^{-r t}\left(\begin{array}{c}
\int_{0}^{y^{*}} \lambda(t, y) s(1-u(t, y)) \psi(y) d y \\
+\int_{y^{*}}^{+\infty} \lambda(t, y)\left(s(1-u(t, y))-\theta_{t} q\left(\theta_{t}\right) u(t, y)\right) \psi(y) d y
\end{array}\right) .
\end{aligned}
$$

Next, we can write down the FOC:

$$
\begin{gathered}
\frac{\partial \mathcal{H}}{\partial \theta_{t}}=0 \Longleftrightarrow-c \bar{u}_{t}+\left(q\left(\theta_{t}\right)+\theta_{t} q^{\prime}\left(\theta_{t}\right)\right) \int_{y^{*}}^{+\infty} \lambda(t, y) u(t, y) \psi(y) d y=0, \\
\frac{\partial H}{\partial y_{t}^{*}}=0 \Leftrightarrow c \theta_{t}+d-\lambda\left(t, y^{*}\right) \theta_{t} q\left(\theta_{t}\right)=0,
\end{gathered}
$$

$$
\begin{aligned}
\frac{\partial \mathcal{H}}{\partial u(t, y)} & =\left(\frac{\partial}{\partial t} \lambda(t, y)-r \lambda(t, y)\right) e^{-r t} \psi(y) \\
& \Leftrightarrow\left\{\begin{array}{c}
-y+(r+s) \lambda(t, y)=\frac{\partial}{\partial t} \lambda(t, y), y<y^{*} \\
-y-\left(c \theta_{t}+d\right)+\left(r+s+\theta_{t} q\left(\theta_{t}\right)\right) \lambda(t, y)=\frac{\partial}{\partial t} \lambda(t, y), y>y^{*}
\end{array}\right\}
\end{aligned}
$$

Let us now focus on the steady state. We note that the marginal value of an employed worker of type $y$ is, in steady state:

$$
\begin{aligned}
\lambda(t, y) & =\frac{y}{r+s} \text { for } y<y^{*} \\
\lambda(t, y) & =\frac{y+c \theta+d}{r+s+\theta q(\theta)} \text { for } y>y^{*} .
\end{aligned}
$$


Substituting into (6) allows to compute $y^{*}$, and we get

$$
y^{*}=\frac{(c \theta+d)(r+s)}{\theta q(\theta)} .
$$

This condition defines the socially optimal search threshold for the workers. We can check that $\lambda$ is continuous at $y=y^{*}$. Finally in steady state we have $u(t, y)=s /(s+\theta q(\theta))=u$ for all $y>y^{*}$. It follows that $\bar{u}=u\left(1-\Psi\left(y^{*}\right)\right)$ and, substituting (7) into (5), we get

$$
c\left(r+s-\theta^{2} q^{\prime}(\theta)\right)=\left(E\left(y \mid y>y^{*}\right)+d\right)\left(q(\theta)+\theta q^{\prime}(\theta)\right) .
$$

This condition defines the socially optimal job creation condition.

\subsection{Comparing equilibrium and optimum.}

To compare the equilibrium and the optimum, we need to confront (8)-(9) with (4)-(3). Comparing the equilibrium and optimum job creation condition, i.e. (3) and (9), it is straightforward to check that the usual Hosios condition $\varphi=-\theta q^{\prime}(\theta) / q(\theta)$ must hold. However, this condition is no longer sufficient. For the two worker search condition to match, we would need in addition that

$$
\varphi=\frac{d}{c \theta+d}
$$

which generally does not hold.

The term $c \theta$ in the denominator of the preceding formula captures the congestion externality exerted by an unemployed worker who decides to search. This decision would reduce $\theta$ and to prevent it from falling, vacancies have to rise by an amount $\theta$, implying that an extra vacancy $\operatorname{cost} c \theta$ must be spent. This extra cost is taken into account by the central planner but not by the individual worker. If the worker's appropriability level is equal to the ratio between his private search cost $d$ and the social one $c \theta+d$, then the congestion externality is internalized.

So far there is nothing new in this line of reasoning and it does not highlight why here (contrary to the usual case) the Hosios conditions fail 
to internalize the congestion externalities. The reason is that this negative externality is exerted upon an unemployed worker of average productivity, whereas the marginal unemployed worker only takes into account his own productivity level when considering the gains from search.

Consequently, even at the Hosios conditions, the degree to which the marginal worker internalizes the congestion problem is inadequate, because his productivity differs from the productivity of the workers upon which the externality is exerted (a "quality effect"). Since the marginal worker is less productive than the average, this effect tends to lead to too much worker search. Therefore we expect the critical productivity level to be lower in the market equilibrium than in the centrally planned solution if the Hosios conditions hold - since the usual congestion externalities are internalized at the Hosios conditions, only the quality effect dominates.

The following Proposition formally shows that, if the Hosios conditions hold, both labor market tightness and the critical productivity level (and hence the average productivity of the employed) are too low in the decentralized equilibrium compared to the social optimum.

Proposition 1 - Assume $q(\theta)=\theta^{-\alpha}$ and $\varphi=\alpha$. Then

$$
\begin{aligned}
& y_{M}^{*}<y_{S P}^{*}, \\
& \theta_{M}^{*}<\theta_{S P}^{*} .
\end{aligned}
$$

Proof - Assume $q(\theta)=\theta^{-\alpha}$ and $\varphi=\alpha$. Clearly, then, in the $\left(\theta, y^{*}\right)$ plane the decentralized worker search schedule WS defined by (4) and the socially optimal worker search schedule SSP defined by (8) intersect only once at

$$
\theta=\tilde{\theta}=\frac{d(1-\alpha)}{c \alpha}
$$

Furthermore, computing the derivative of the RHS of (8) shows that this is the minimum point of SSP. It is straightforward to compute the value of $y^{*}$ at this intersection point. It is given by 


$$
\tilde{y}^{*}=(r+s) \frac{c^{1-\alpha} d^{\alpha}}{(1-\alpha)^{1-\alpha} \alpha^{\alpha}}
$$

Next, we can show that the decentralized JC condition (3) coincides with the social one (8). Their common expression is

$$
\bar{y}+d=\frac{c(r+s)}{1-\alpha} \theta^{\alpha}+\frac{\alpha}{1-\alpha} c \theta .
$$

Substituting (10) into that equation, and comparing with (11) we see that at $\theta=\tilde{\theta} \bar{y}=\tilde{y}^{*}$ along the job destruction locus. Since $\bar{y}>y^{*}$, it must be that the common JD locus is below the intersection point between SSP and WS at $\theta=\tilde{\theta}$. Since JD is upward sloing in the $\left(\theta, y^{*}\right)$ plane, SSP is U-shaped with a minimum at $\theta=\tilde{\theta}$, and WS downward sloping, JD intersects intersects WS before SSP. This proves the claims of the proposition.

QED

Figure 3 illustrates Proposition 1. If $\varphi=\alpha$ the Hosios conditions hold and the JC loci (9) and (3) coincide. The social planner's optimal worker search condition is given by SSP (defined by (8)) and the corresponding market condition is WS (expressed by (4)). These two conditions intersect at a point $\tilde{\theta}$, which furthermore is the minimum point of SSP. The JC condition is below the intersection point, so that it cuts WS before SSP, on the right of this minimum point.

The LHS of (8) and (4) is the marginal benefit - expressed in terms of the additional flow of output generated by that worker when eventually employed - of putting an additional unemployed worker into active search. The corresponding RHSs are the social and private marginal costs of doing so, respectively. The social planner considers the congestion cost imposed on the average job seeker, while at the Hosios conditions the marginal job seeker only internalizes the congestion costs imposed on marginal workers. 


\section{Welfare effects of active labor market poli- cies}

Now we assume that the government pursues an active labor market policy, understood as a subsidy to job search which reduces the cost of search from $d$ to $d-\tau$. I assume that somehow the government can enforce this policy, i.e. the subsidy $\tau$ is not paid to the workers who do not search. That is, the unemployed's search activity is "monitored" and $\tau$ is paid only upon proof of search activity. This makes the policy resemble more an active labor market policy than an unemployment benefit system.

Furthermore, all unemployed job seekers are entitled to the subsidy, irrespective of their productivity or employment history. The analysis could deliver different results if, say, the subsidies were targeted to the low productivity workers ${ }^{3}$.

I assume the subsidy is financed by a lump-sum tax levied on all workers. This tax does not introduce distortions in equilibrium determination, so the above computations for the equilibrium endogenous variables remain correct. However the present discounted value of the tax now has to be deducted from the welfare of the employed and the unemployed, as defined in equations (3) and (2).

To compute this tax burden, we note that for a given search threshold $y^{*}$ and a given distribution of unemployment rates by productivity levels $u_{0}(y)$, the initial stock of unemployed workers actually searching is given by

$$
\bar{u}_{0}=\int_{y^{*}}^{+\infty} u_{0}(y) \psi(y) d y
$$

The total number of employed workers of types $y>y^{*}$ at date $t$ is given

\footnotetext{
${ }^{3}$ In particular, in Saint-Paul (1998), active labor market policies harm the insiders, because they raise the search effort of outsiders. But here the insiders would benefit from the policy should they lose their job, which raises their bargaining power. Therefore, active policies may have very different effects on the welfare of incumbent workers depending on how they are designed.
} 
by $1-\Psi\left(y^{*}\right)-\bar{u}_{t}$. Consequently, the law of motion of $\bar{u}_{t}$ is

$$
\frac{d}{d t} \bar{u}_{t}=s\left(1-\Psi\left(y^{*}\right)-\bar{u}_{t}\right)-\theta q(\theta) \bar{u}_{t}
$$

The solution is

$$
\bar{u}_{t}=\left(\bar{u}_{0}-\bar{u}_{\infty}\right) e^{-(s+\theta q(\theta)) t}+\bar{u}_{\infty}
$$

where

$$
\bar{u}_{\infty}=\frac{s\left(1-\Psi\left(y^{*}\right)\right)}{s+\theta q(\theta)} .
$$

The tax cost of the subsidy at date $t$ is

$$
T_{t}=\tau \bar{u}_{t}
$$

therefore the PDV of this tax is

$$
\int_{0}^{+\infty} T_{t} e^{-r t} d t=\tau H
$$

where

$$
\begin{aligned}
H & =\frac{\bar{u}_{0}}{r+s+\theta q(\theta)}+\frac{\bar{u}_{\infty}(s+\theta q(\theta))}{r(r+s+\theta q(\theta))} \\
& =\frac{\bar{u}_{0}}{r+s+\theta q(\theta)}+\frac{s\left(1-\Psi\left(y^{*}\right)\right)}{r(r+s+\theta q(\theta))} .
\end{aligned}
$$

The utility function of an unemployed worker who is searching and has a productivity $y$ can then be rewritten as

$$
V_{u}(y)=\frac{(\tau-d)(r+s)+\varphi \theta q(\theta) y}{r(r+s+\varphi \theta q(\theta))}-\tau H .
$$

Similarly for the employed:

$$
V_{e}(y)=\frac{(\tau-d)(r(1-\varphi)+s)+\varphi(\theta q(\theta)+r) y}{r(r+s+\varphi \theta q(\theta))}-\tau H .
$$

We also need to discuss how $\tau$ affects the job destruction and worker search conditions. For this it is enough to replace $d$ by $d-\tau$ in those conditions, and we get 


$$
\begin{aligned}
\bar{y}+d-\tau & =\frac{c(r+s)}{(1-\varphi) q(\theta)}+\frac{\varphi}{1-\varphi} c \theta, \\
y^{*} & =\frac{(d-\tau)(r+s)}{\varphi \theta q(\theta)} .
\end{aligned}
$$

We see that in the $\left(\theta, y^{*}\right)$ plane an increase in $\tau$ shifts WS down and JC to the left. Labor market tightness unambiguously falls while the change in the average quality of workers is ambiguous.

The subsidy to job search raises the opportunity cost of work for those worker types who actively search. This increases wage pressure thus reducing profitability and the incentives to post vacancies. Therefore $\theta$ falls. Furthermore at the extensive margin, given $\theta$, more workers want to search. As such this effect tends to further reduce $\theta$ because the additional workers are less productive than average, thus reducing again the value of posting vacancies. However the fall in $\theta$ per se tends to discourage job search, and if this fall is strong enough worker quality actually goes up, and so does long-term unemployment, despite the subsidy to job search.

The effects of $\tau$ are qualitatively similar to those of $\varphi$ : Both parameters shift the two loci in the same direction. A greater $\varphi$ increases the worker's power in wage setting through the rent they can extract from the employer, while $\tau$ does it through their outside option in bargaining. A greater $\varphi$ reduces $y^{*}$ given $\theta$ because the prospects of greater rents induce more workers to search, while a greater $\tau$ does so through direct subsidization of search.

We are now in a position to discuss the effects of ALMP on welfare. We first start with social welfare and then proceed to discuss the welfare of different categories of workers.

\subsection{Social welfare}

While we already know that the Hosios conditions per se are insufficient to restore efficiency, we can analyze which combination of $\varphi$ and $\tau$ delivers the first best. Admittedly this is a contrived exercise since $\tau$ presumably is 
a policy variable while $\varphi$ is not. But $\varphi$ can be targeted indirectly by the policymaker through regulations such as severance payments ${ }^{4}$.

We need to match the optimality condition with the equilibrium ones. The equilibrium job creation condition (14) must coincide with the optimality condition (9) for $y^{*}=y_{S P}^{*}$ and $\theta=\theta_{S P}$. Let $\eta=-\theta_{S P} q^{\prime}\left(\theta_{S P}\right) / q\left(\theta_{S P}\right)$. Then eliminating $\bar{y}=E\left(y \mid y>y_{S P}^{*}\right)$ between these two conditions and dropping the "SP" subscript we get the following:

$$
\tau=\frac{c(r+s+\eta \theta q(\theta))}{q(\theta)(1-\eta)}-\frac{c(r+s+\varphi \theta q(\theta))}{q(\theta)(1-\varphi)} .
$$

This defines a decreasing, concave relationship, called OJC, in the $(\varphi, \tau)$ plane which goes through the point $(\eta, 0)$. This relationship depicts the combinations of $\varphi$ and $\tau$ that make firms internalize the congestion externality in job search. These are the combinations that deliver the correct social opportunity cost of labor. If for example the fraction of the surplus appropriated by the worker is greater than the Hosios level, then the cost of labor is too high and one has to tax search to reduce the worker's outside option in bargaining, thus bringing the cost of labor down back to the correct level from the social planner's perspective.

Similarly, we can match the equilibrium worker search condition (15) with the optimality one (8) and we get

$$
\tau=-\varphi c \theta+(1-\varphi) d
$$

This defines another decreasing, linear relationship between $\tau$ and $\varphi$. These are the combinations of $\varphi$ and $\tau$ that deliver the socially optimal benefit of search to the unemployed workers, reflecting both the quality and congestion externalities. Since we know that the latter is internalized by

\footnotetext{
${ }^{4}$ See for example the analysis in Saint-Paul, 2014. Of course, how allocative severance payments are depends on the degree of commitments of firms and workers in bargaining. Under full commitment, a severance payment will be offset by a transfer upon recruitment, and will have no effect on equilibrium job creation. However, under imperfect commitment, the severance payment will raise the worker's threat point in bargaining whenever wages are being renegotiated.
} 
workers at $\varphi=\eta$, only the (negative) quality externality remains, implying that along this locus $\tau<0$ at $\varphi=\eta$ : search must be taxed for workers to internalize the negative effect of the marginal job seeker on the average quality of the pool $^{5}$.

The joint determination of the optimal $\varphi$ and $\tau$ is depicted on Figure 4. The OJC locus depicts the relationship (16), while OWS represents (17). The optimal solution can then be characterized relative to the benchmark Hosios condition without ALMP as follows:

Proposition 2 - The optimal values of $\varphi$ and $\tau$ are such that $\varphi>\eta$ and $\tau<0$

PROOF - Clearly, from the RHS of (16), we have that $\lim _{\varphi \rightarrow 1} \tau=-\infty$ along OJC. We already know that the RHS of (16) is greater than that of (17) at $\varphi=\eta$. Since the RHS of (17) remains finite at $\varphi=1$, by continuity there exists a value of $\varphi \in(\eta, 1), \varphi^{*}$, at which OJC and OWS cross. Clearly, the corresponding $\tau^{*}$ is negative. Furthermore, the RHS of (16) is a concave function of $\varphi$, while that of (17) is affine. Therefore, there is at most one other intersection point between OJC and OWS, and it must be such that $\varphi<\eta$. For $\varphi=0$, the RHS of (17) is equal to $d$. The RHS of (16) is equal to

$$
\frac{c(r+s+\eta \theta q(\theta))}{q(\theta)(1-\eta)}-\frac{c(r+s)}{q(\theta)}=\frac{c \eta}{1-\eta}\left(\frac{r+s}{q(\theta)}+\theta\right) .
$$

${ }^{5}$ Indeed this can be checked algebraically, by noting that

$$
\frac{c \theta_{S P}+d}{\theta_{S P} q\left(\theta_{S P}\right)}(r+s)<\frac{c\left(r+s+\eta \theta_{S P} q\left(\theta_{S P}\right)\right)}{q\left(\theta_{S P}\right)(1-\eta)}-d .
$$

and then showing that this inequality is equivalent to

$$
0<\frac{\eta}{1-\eta} c \theta-d
$$

Finally, it is immediate that at $\varphi=\eta$ the RHS of (17) is negative. 
Now, from (9), and using (8), we have that

$$
\begin{aligned}
\frac{c}{1-\eta}\left(\frac{r+s}{q(\theta)}+\eta \theta\right) & =d+\bar{y} \\
& >d+y^{*} \\
& =d+(r+s) \frac{c}{q(\theta)}+d \frac{r+s}{\theta q(\theta)},
\end{aligned}
$$

from which it follows that $\frac{c \eta}{1-\eta}\left(\frac{r+s}{q(\theta)}+\theta\right)>d$. Therefore OJC is above OWS at $\varphi=0$, and, by concavity, also over $\left[0, \varphi^{*}\right)$. Therefore, the only intersection between OJC and OWS is $\left(\varphi^{*}, \tau^{*}\right)$.

QED

The optimal policy is to raise the worker's rent beyond the Hosios level while at the same time implementing a negative active labor market policy which taxes job search (we ignore feasibility constraints on such policies). This is just the opposite of what, say, an OECD report would recommend.

One way to interpret this result is as follows: starting from the Hosios condition value of $\varphi$, search must be taxed because of the quality externality. But taxing search reduces the cost of labor, leading to too high a vacancy level. To compensate for that, one must further raise the worker's bargaining power, which in turn must lead to a higher tax on job search ${ }^{6}$.

\subsection{Effect on the welfare of different types of workers}

I now study which groups gain and lose from ALMPs. In the sequel I will assume that an increase in $\tau$ has a "normal" effect on $y^{*}$, i.e. that $y^{*}$ falls ${ }^{7}$. As a result it must be that $d H / d \tau>0$, both because $y^{*}$ falls (a greater

\footnotetext{
${ }^{6}$ Note however that this process converges to a consistent pair $(\varphi, \tau)$ only because (i) OJC becomes steeper relative to OWS as one moves to the right, and (ii) the opposite strategy of reducing $\varphi$ and compensating by a raise in $\tau$ does not converge because OWS and OJC fail to cross on the left of $\varphi=\eta$. This suggests that for some different version of the model one could have an optimum with $\tau>0$ and $\varphi<\eta$ instead. Intuitively, what is much more robust is the prediction that the optimal policy must satisfy $\tau(\varphi-\eta)<0$. Hence, if active labor market policy proves to be optimal, it must be accompanied with a reduction in the worker's bargaining power relative to the Hosios level.

${ }^{7}$ Otherwise introducing a subsidy to job search would hardly qualify as "active" labor market policy.
} 
proportion of the population is eligible for the subsidy) and $\theta$ falls (people who do search remain unemployed longer, so the subsidy has to be paid to them for a longer period).

Equations (12) and (13) imply that we can distinguish three kind of effects of the subsidy on different categories of workers:

- The negative direct tax effects are given by $\frac{d}{d \tau}(\tau H)$ and are the same for all workers, including those who do not search. These ones have a utility equal to $-\tau H$ and they clearly are worse-off, unless the change in the subsidy makes them switch from non-search to search.

- The direct positive effect of the subsidy on the utility flow while searching. This effect is given by

$$
\frac{r+s}{r(r+s+\varphi \theta q(\theta))}
$$

for the unemployed and by

$$
\frac{r(1-\varphi)+s}{r(r+s+\varphi \theta q(\theta))}
$$

for the employed. It is therefore stronger for the unemployed than for the employed, as their discounted expected time spent in unemployment is obviously larger. Furthermore this effect does not depend on the worker's productivity $y$.

- The indirect negative effect on utility through the fall in $\theta$. It is equal to

$$
\frac{d \theta}{d \tau}\left(q(\theta)+\theta q^{\prime}(\theta)\right) \frac{\varphi(r+s)(y+d-\tau)}{r(r+s+\varphi \theta q(\theta))^{2}}
$$

for the unemployed and to

$$
\frac{d \theta}{d \tau}\left(q(\theta)+\theta q^{\prime}(\theta)\right) \frac{\varphi(r(1-\varphi)+s)(y+d-\tau)}{r(r+s+\varphi \theta q(\theta))^{2}}
$$

for the employed. We notice that this negative effect is also stronger for the unemployed, for whom the job finding rate matters more than for the employed. Also, this effect is stronger for more productive workers, because they 
appropriate part of the surplus of the match and therefore get higher wages, which makes them lose more from any reduction in job finding rates. This suggests that, controlling for labor market status, more productive workers are more likely to oppose active labor market policies.

The preceding formulas allow us to find out who gains and who loses from an increase in $\tau$ among the employed and the unemployed. Consolidating all the terms spelled out above, we see that the marginal gains can be written as $(r+s) \gamma(y)-\frac{d}{d \tau}(\tau H)$ for the unemployed and $(r(1-\varphi)+s) \gamma(y)-\frac{d}{d \tau}(\tau H)$ for the employed, where

$$
\gamma(y)=\frac{1}{r(r+s+\varphi \theta q(\theta))}+\frac{d \theta}{d \tau}\left(q(\theta)+\theta q^{\prime}(\theta)\right) \frac{\varphi(y+d-\tau)}{r(r+s+\varphi \theta q(\theta))^{2}},
$$

and $\gamma^{\prime}<0$. Therefore we see that an employed worker opposes the increase in $\tau$ iff his productivity level is greater than

$$
\tilde{y}_{e}=\gamma^{-1}\left(\frac{1}{r(1-\varphi)+s} \frac{d}{d \tau}(\tau H)\right)
$$

In particular, if $\tilde{y}_{e}<y^{*}$, all the employed opposed ALMPs.

As for the unemployed, their corresponding critical productivity level is

$$
\tilde{y}_{u}=\gamma^{-1}\left(\frac{1}{r+s} \frac{d}{d \tau}(\tau H)\right)>\tilde{y}_{e}
$$

This inequality means that unemployed searchers are more in favor of active labor market policies than the employed.

However, the long-term unemployed, i.e. those such that $y<y^{*}$, oppose it, except a tiny band of workers who are just below the critical search threshold and who switch their behavior because of the subsidy (but this band would not be tiny if we were considering a non infinitesimal increment in $\tau$ ). Thus, somewhat paradoxically, here most of the long-term unemployed oppose ALMPs, however this is because here worker search only operates through the extensive margin. More generally, though, it makes sense to think that, to the extent that they have to contribute to their costs as taxpayers, the most disenfranchised long-term unemployed do not particularly 
support active labor market policies as it is unlikely to raise their own job finding rate.

This discussion allows us to characterize the constituency in favor of active labor market policy. If $y^{*}<\tilde{y}_{e}$, then the coalition of workers in favor of ALMPs is made of the least productive employed workers, the least productive short-term unemployed, and the most productive long-term unemployed. The opponents are the least productive long-term unemployed, and the most productive employed and job-seekers. As the short-term unemployed are more in favor of ALMPs than the employed, the opponents among the former are more productive than the opponents among the latter. 


\section{REFERENCES}

Boeri, Tito, Conde-Ruiz, Ignacio J. and Galasso, Vincenzo (2012). "The Political Economy of Flexicurity," Journal of the European Economic Association, 10(4), pp. 684-715.

Cahuc, Pierre and Etienne Lehmann (2000), "Should Unemployment Benefits Decrease with the Unemployment Spell ?", Journal of Public Economics, $77,135-153$

Hosios, Arthur J, 1990. "On the Efficiency of Matching and Related Models of Search and Unemployment," Review of Economic Studies, 57(2), pages 279-98, April.

Fredriksson, Per and Bertil Holmlund (2001), "Optimal Unemployment Insurance in Search Equilibrium", Journal of Labor Economics, 19(2), 370399

Krusell, Per, Mukoyama, T. and A. Sahin (2010), "Labour Market Matching with Precautionary Savings and Aggregate Fluctuations", Review of Economic Studies, 77, 1477-1507

Lehmann, Etienne and Bruno van der Linden (2007), "On the Optimality of Search Matching Equilibrium When Workers Are Risk Averse", Journal of Public Economic Theory, 9(5), 867-884

Michau, Jean-Baptiste (2013), "Optimal Labor Market Policy with Search Frictions and Risk-Averse Workers", Ecole Polytechnique working paper

Mortensen, Dale and Christopher Pissarides (1994), "Job Creation and Job Destruction in the Theory of Unemployment", Review of Economic Studies, 61, 3, 397-415

Mortensen, Dale and Christopher Pissarides (2003), "Taxes, Subsidies, and Equilibrium Labor Market Outcomes", in Designing Inclusion: Tools to Raise Low-End Pay and Employment in Private Enterprise, Edmund Phelps, ed., Cambridge University Press

Ortega, Javier (2000),"Pareto-Improving Immigration in an Economy with Equilibrium Unemployment," Economic Journal, 110(460), 92-112

Saint-Paul, Gilles (1998), "A Framework for Analyzing the Political Sup- 
port for Active Labor market Policy", Journal of Public Economics, 67, 151165

(2000), The Political Economy of Labour Market Institutions, Oxford University Press

- (2014), Frictions and Institutions. Copenhagen: Bookboon (http://bookboon.com/fr/frictions-and-institutions-ebook)

Wright, Randall (1986), "The redistributive roles of unemployment insurance and the dynamics of voting," Journal of Public Economics, 31(3), pages 377-399. 


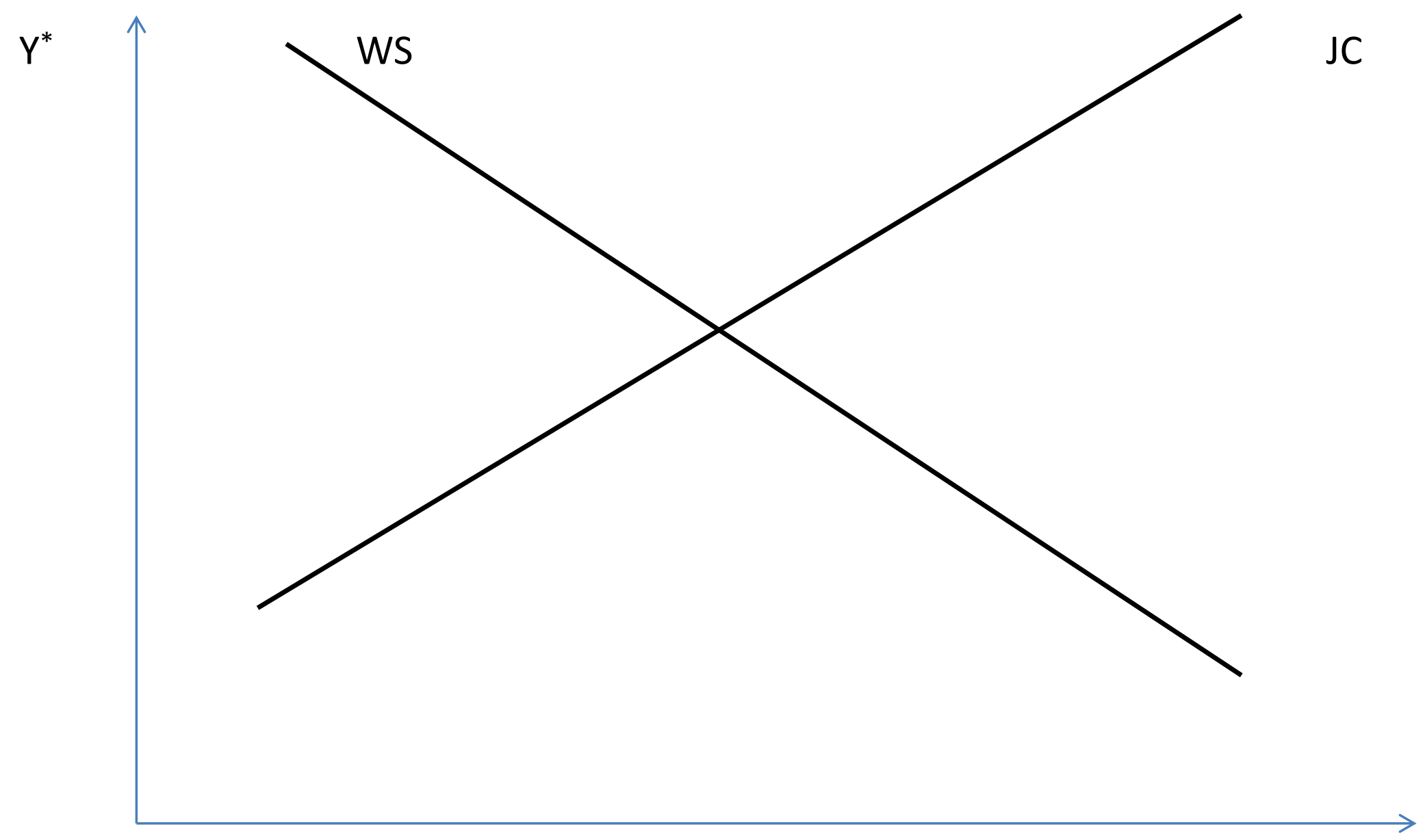

Figure 1 - Equilibrium determination 


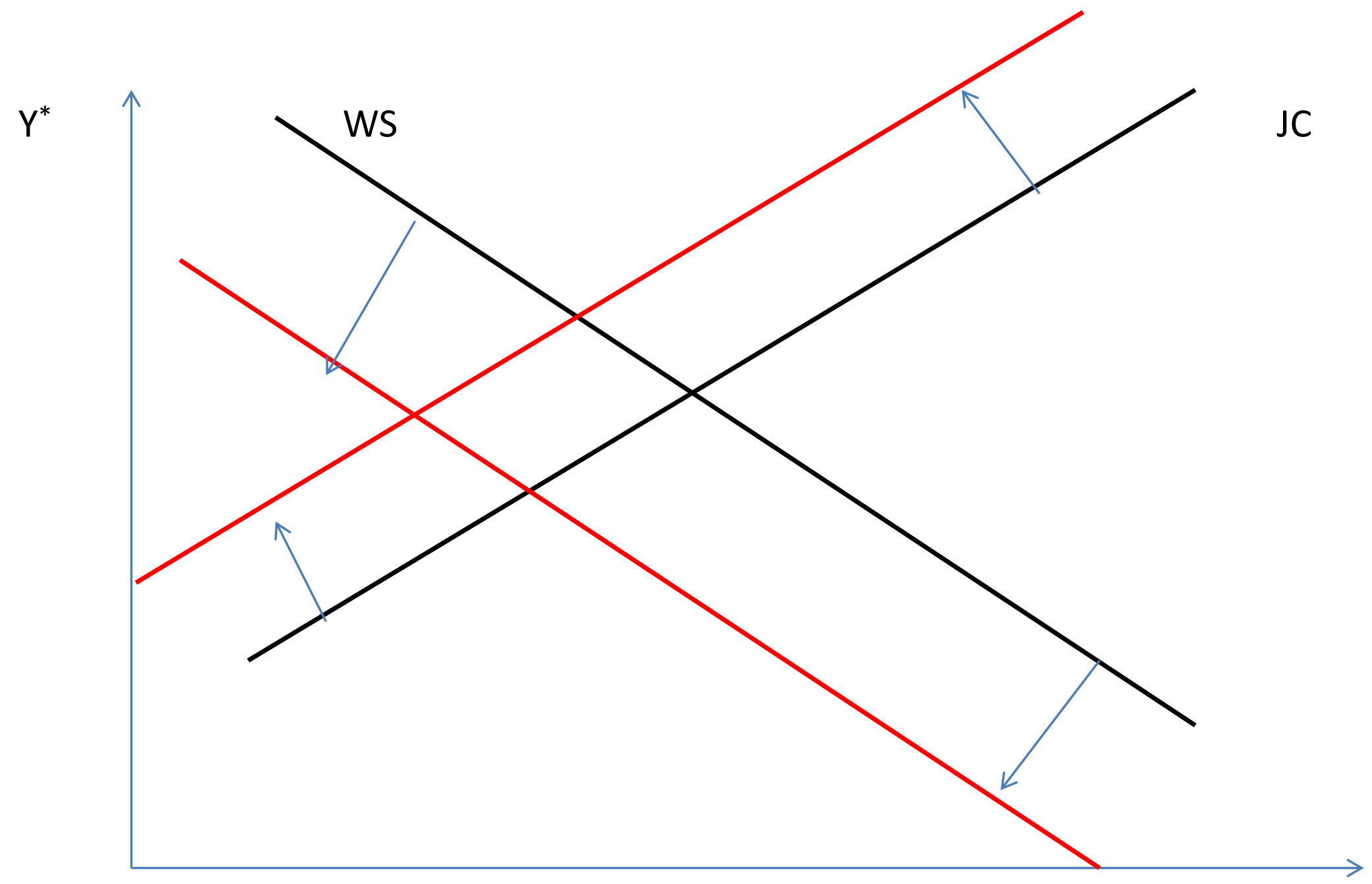

Figure 2 - Impact of an increase in the worker's bargaining power 


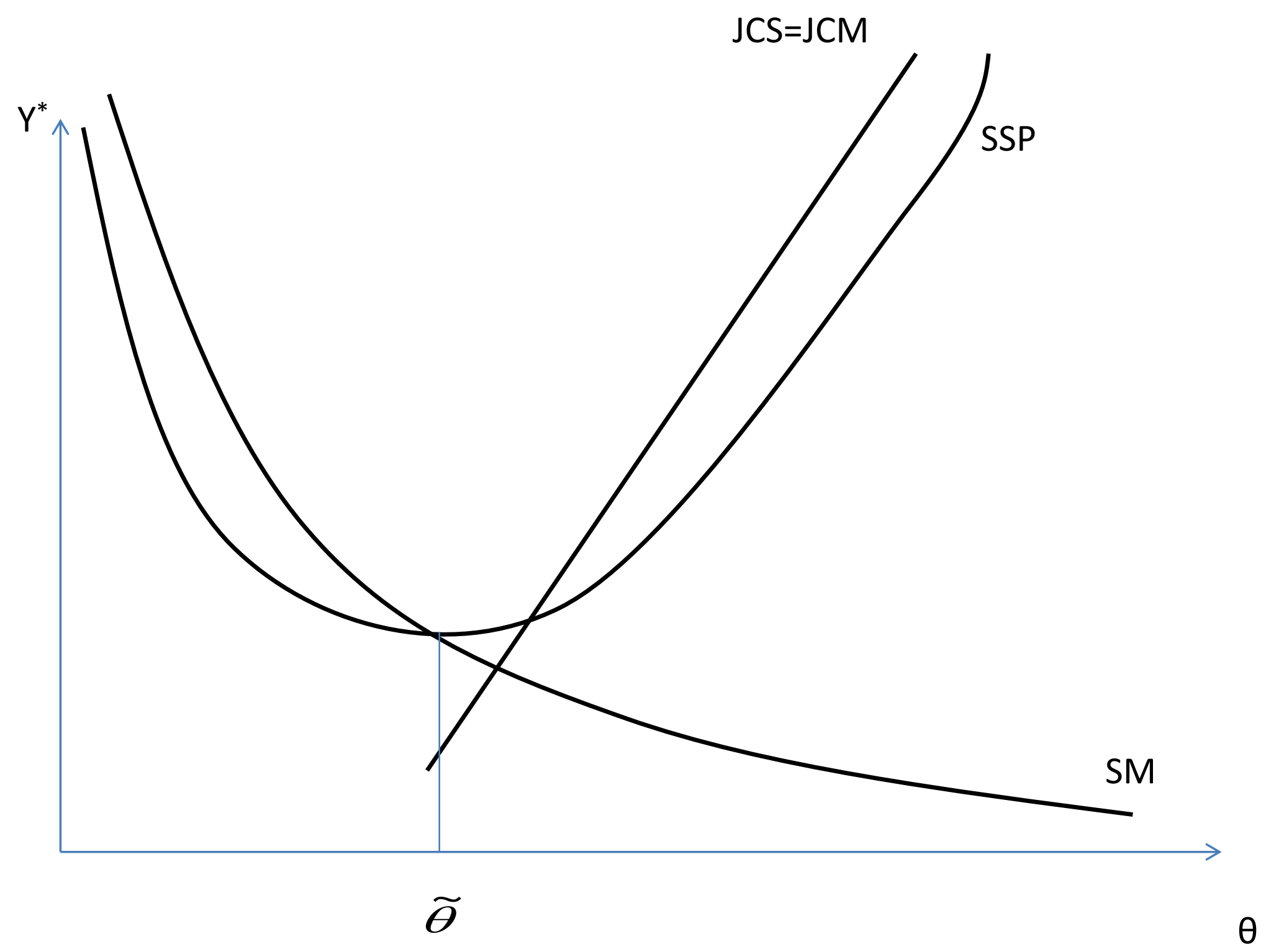

Figure 3 - if Hosios holds, too much worker search 


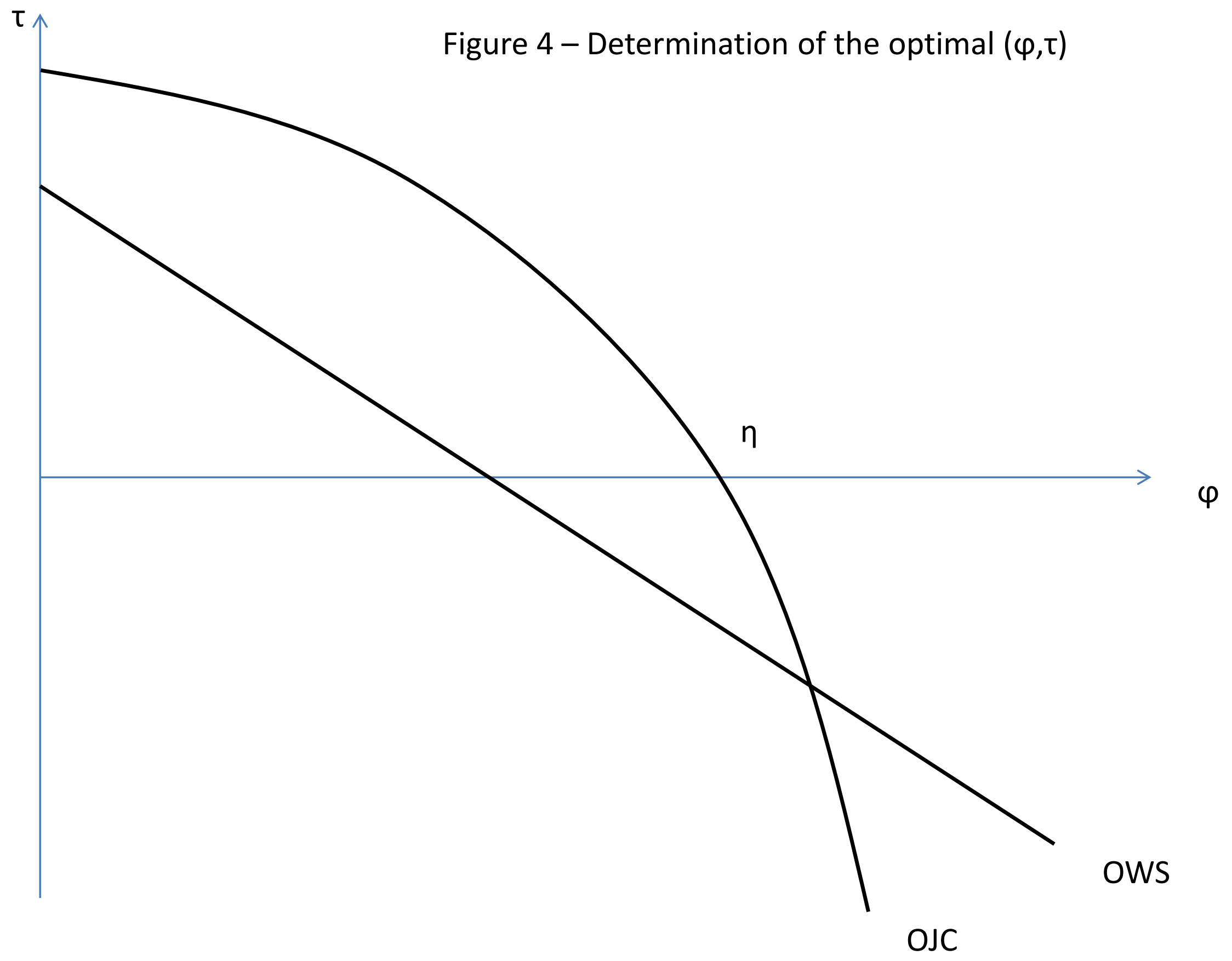

